\title{
People Not Machines: Authorship and What It Means in the Berne Convention
}

\author{
Jane C. Ginsburg
}

Published online: 29 January 2018

(C) Max Planck Institute for Innovation and Competition, Munich 2018

In 1992 Sam Ricketson delivered the annual Manges Lecture at Columbia Law School, presciently titled People or Machines: The Berne Convention and the Changing Concept of Authorship. ${ }^{1}$ As Professor Ricketson systematically developed the inquiry, it became clear that "People or Machines" in fact meant "People Not Machines". More than 25 years later, with the ensuing evolution of machines capable of generating outputs often indistinguishable from human-authored works, I suggest that conclusion remains correct, perhaps even more urgently so than in 1992.

\section{People or Machines}

In his 1992 article, Professor Ricketson acknowledged that the Berne Convention did not define authorship, but contended that "there was nonetheless a basic agreement between the contracting states as to the meaning of the term, and, because of this, it was thought unnecessary to define it ... it seems only logical to interpret 'authors' and 'authorship' for the purposes of the Convention as pertaining to the persons who created such works". Moreover, surveying Berne's text, Professor Ricketson found that the "leitmotiv" of human authorship undergirded most of the articles of the Convention.

\footnotetext{
${ }^{1}$ Revised and published at 16 Colum.-VLA J. L. \& Arts 1 (1991).

Many thanks for expert research assistance to Luke Budiardjo, Columbia Law School class of 2018. This Editorial is based on a chapter forthcoming in Graeme Austin, Andrew Christie, Andrew Kenyon and Megan Richardson (eds.) Interconnected Intellectual Property (Cambridge University Press 2018).

J. C. Ginsburg $(\bowtie)$

Morton L. Janklow Professor of Literary and Artistic Property Law at Columbia Law School,

New York, USA

e-mail: ginsburg@law.columbia.edu
} 
Arguably, Berne's commitment to human authorship wavers with respect to cinematographic works, since Art. $14^{\text {bis }}(2)$ permits vesting copyright in the "maker" of a cinematographic work. Professor Ricketson, however, cautioned against making the exception the rule, and especially against confusing first ownership and authorship, whose human essence that same article in fact reinforces, by denominating film producers a "makers", rather than "authors".

Professor Ricketson also addressed the then-recent 1991 WIPO Proposal for Protection of Computer-Produced Works, which (following the lead of the 1988 UK Copyright, Designs and Patents Act) considered vesting original ownership of copyright in the physical or legal entity who undertook the arrangements necessary for the creation of the work, and also would have departed from Berne norms with respect to duration and moral rights. Professor Ricketson observed that the proposal assumed that these computer-aided productions did have human authors, but that it was impossible to identify their individual contributions. Nonetheless, anticipating the accomplishments of today's algorithm-driven productions, Professor Ricketson cautioned:

This reference to human contributors, however, may well prove fanciful as the development of expert systems and artificial intelligence increases the likelihood of the creation of purely computer-generated works. Indeed, we may already be at this stage in the case of electronic data bases where the work of compilation and assembly can be carried out in accordance with the operation of specifically designed computer programs. In such instances, the notion of human contribution becomes meaningless, unless traced back to the creator of the data base program or expert system ... such productions ... lack the necessary requirements for recognition as works of authorship under the Berne Convention.

Professor Ricketson pushed his forceful defense of human authorship further:

In light of the general propositions put forward concerning the concept of authorship under the Berne Convention, one might query whether there still remains much in this "soul" [of copyright] worth protecting. ... [One might argue that we should] declare that copyright is not really concerned with the protection of the fruits of human authorship, but only concerned with the question of commercial value, however that value is embodied or arrived at ... such a change ... would make it possible to bring all new forms of technological creation within the broad umbrella of the Berne Convention ... rather than [adopting] tailor-made ... sui generis protection [for these new forms of creation]. ... While this suggested approach appears attractive in a pragmatic sense, I do not believe that we should move in this way ... there are powerful arguments, both in principle and necessity, in favor of retaining this human-centered notion of authorship and authors' rights. 


\section{"Purely Computer-Generated Works"?}

Professor Ricketson anticipated the prospect of works whose authorship would be difficult to establish, not because of a plethora of human and non-human contributors (as WIPO expected), but because of the absence of any human whose participation in the computer's output would be sufficiently proximate and original to constitute authorship. Today, while some debate whether the human input into computer-generated outputs is in fact too attenuated to identify a human author, ${ }^{2}$ the burgeoning of "computer generated works" - outputs of digital neural networks that have "taught themselves" to combine rules of literary, musical or artistic assembly after being "trained" on a database of pre-existing works - suggests that purely computer-generated works already exist or at least are in near prospect. For example, programs exist which compose musical scores by utilizing "deep learning" algorithms to learn from examples of classical music ${ }^{3}$; other programs devise melodies and generate a full musical composition and performance in response to a user's entry of basic selection criteria like tempo and genre. ${ }^{4}$ Google Translate employs a system that "learns" from experience and improves its algorithm with multiple iterations of its program or through a neural net that is simply "trained" and is not programmed with specific procedural algorithms. ${ }^{5}$ "Paul," the robotic portraitist, sketches human faces in the artistic style of its erstwhile artist programmer. ${ }^{6}$

If the human intervention in producing these outputs does not exceed requesting the computer to generate a literary, artistic or musical composition of a particular style or genre, one may properly consider these works to be "computer-generated" because the human users do not contribute sufficient "intellectual creation" to meet minimum standards of authorship under the Berne Convention. Offline, merely

\footnotetext{
${ }^{2}$ See, e.g., James Grimmelmann, "There's No Such Thing as a Computer-Authored Work - And It's a Good Thing, Too", 39 Colum. J. L. \& Arts 403 (2016). The "next Rembrandt" portrait created by selecting and combining features from a database of all of Rembrandt's paintings involves a great deal of sophisticated computer programming, but it is essentially a mash-up produced through persistent human supervision and direction of the inputs. See https://www.nextrembrandt.com/; https://www.youtube.com/ watch?v=IuygOYZ1Ngo.

3 For example, the "IAMUS" program has produced works of contemporary classical music that human musicians have performed and recorded; see, e.g., Sylvia Smith, Iamus: "Is this the 21st century's answer to Mozart?” BBC News (Jan. 3, 2013), http://www.bbc.com/news/technology-20889644.

4 See JukeDeck.com/make (prompting users to input basic parameters (tempo, genre, instruments, duration, and climax) and then creating a musical work based on the defined parameters using a neural network trained with musical examples). For a broader survey of recent efforts to implement artificial intelligence techniques in music creation, see Alex Marshall, "From Jingles to Pop Hits, A.I. Is Music to Some Ears", N.Y. Times (Jan. 22, 2017).

5 According to the translation program's developers, "[ $\mathrm{t}]$ he machine is not 'analyzing' the data the way that we might, with linguistic rules that identify some of them as nouns and others as verbs. Instead it is shifting and twisting and warping the words around in the map. ... Some of the [developments in Google's translation system were] not done in full consciousness. [The researchers] didn't know themselves why they worked". Gideon Lewis-Kraus, "The Great A.I. Awakening", N.Y. Times (Dec. 14, 2016).

6 See http://www.bbc.co.uk/programmes/articles/1f4Z6k7Clz6qY6Q2K56nkzZ/robotticelli-the-mechanicalmarvel-creating-extraordinary-works-of-art.
} 
giving a command does not make one an "author": Pope Julius II may have commissioned the painting of the ceiling of the Sistine Chapel; from a Berne perspective (at the very least), the author of the frescos remains Michelangelo. Were a future Julius IV to instruct a computer to interrogate its comprehensive database of religious art to devise and paint a sequence of Old Testament scenes, that Julius would no more be the author of the output than was his forebear.

\section{Consequences for International Copyright}

But, if artificial intelligence at least in some instances effaces human authorship, what of the copyright status of the outputs? Professor Ricketson adverted to, and repulsed, copyright objectives based in "commercial value" rather than "protection of the fruits of human authorship". Copyright, however, reposes on two pillars (whose respective widths vary in common law and civilian systems): one (generally attributed to civil law states), the natural rights of the author, a rationale that roots exclusive rights in personal creativity, and that largely underpins the Berne Convention; the other (most frequently associated with common law countries), incentives to create, to invest in creativity, and to disseminate works for the general benefit of society. Protection of commercial value aligns with the latter justification for copyright. But Berne does not completely ignore this basis, as one may infer from its accommodation of producer-ownership of copyright in cinematographic works, as well as its provision of shorter terms for works of arguably borderline authorship, such as photographs and applied art. On the other hand, acknowledging that Berne harbors incentive rationales for copyright is hardly the same thing as contending that Berne embraces a concept of copyright in which incentive/ investment rationales supply the sole justification for exclusive rights. The latter concept entertains the expulsion of human authors, and, given Berne's humanist cast, that would purge copyright of its "soul".

Justifications based in incentives to produce works that promote the progress of knowledge might sustain some, certainly less extensive, form of intellectual property protection. The premise underlying incentive justifications - that without a property right, desirable works will not be produced - however, requires substantiation. One must inquire whether computer-generated outputs in fact need the impetus of exclusive rights, or instead if sufficient other incentives already exist, for example higher up the chain, through copyright or patent protection of the software programs, patent protection of the specialized machinery to produce works of fine and applied art, and copyright or (in the EU) sui generis protection of the database the software consults. This empirical inquiry should be undertaken before any Berne member states beyond the generally common law nations that have already emulated the UK approach ${ }^{7}$ extend copyright or sui generis protections to purely computer-generated works. Regardless, because lack of human authorship

\footnotetext{
7 See Robert C. Denicola, "Ex Machina: Copyright Protection for Computer-Generated Works", 69 Rutgers U. L.R. 251 (2016) for a survey of national copyright laws in Ireland, New Zealand, South Africa, Hong Kong and India, emulating the UK Copyright, Designs and Patents Act 1988 c.48 § 9(3) example of denominating as the "author" of a computer-generated work as "the person by whom the arrangements
} 
would disqualify such outputs from Berne subject matter under Art. 2, other Berne members incur no obligation to protect purely computer-generated works even if their countries of origin choose to cover them by copyright. ${ }^{8}$

Footnote 7 continued

necessary for the creation of the work are undertaken" and of providing a shorter term of copyright without moral rights.

8 See Berne Conv. Art. 5(1): “Authors shall enjoy, in respect of works for which they are protected under this Convention, in countries of the Union other than the country of origin, the rights which their respective laws do now or may hereafter grant to their nationals, as well as the rights specially granted by this Convention" (emphasis added). 